\title{
ASPECTOS CLÍNICOS DA CANDIDOSE BUCAL DE PACIENTES HOSPITALIZADOS - RELATO DE CASOS
}

Allana PIVOVAR, Priscilla PERLAS, Estevan DISCINI, Adilson Soares de LIMA

A candidose é uma infecção fúngica causada pela família Candida sp, sendo a espécie albicans a mais comum. Vários fatores de risco podem contribuir para o surgimento da doença na boca que apresenta manifestações de aspecto clínico variável. Este trabalho visa apresentar três casos clínicos de candidose bucal em pacientes internados em hospital para tratamento de doenças infectocontagiosas. Nos três casos, os pacientes eram HIV positivos, apresentavam placas branco-amareladas removíveis à raspagem e localizadas no palato, mucosa jugal e borda lateral da língua. Os pacientes dos casos 1 e 2 eram do sexo masculino. Nos casos 1 e 3 , os pacientes eram portadores de tuberculose pulmonar. O paciente do caso 2 tinha o diagnóstico de tuberculose ganglionar e meningoencefalite. Ele apresentava cáries, doença periodontal, anquiloglossia e leucoplasia pilosa oral. O diagnóstico de candidose pseudomembranosa foi estabelecido baseado no aspecto clínico das lesões e o tratamento com fluconazol levou a remissão completa da infecção dentro de sete dias. O cirurgião dentista precisa estar apto a diagnosticar e a tratar a candidose orofaríngea bem como a reconhecer o significado da mesma como um marcador de supressão imunológica e progressão pela doença pelo HIV.

Palavras chaves: candidíase; imunodeficiência; mucosa bucal; fungo. 